\title{
Glycogen-rich Clear Cell Carcinoma of the Breast: A Comprehensive Review
}

\author{
Semir Vranic, MD, PhD, ${ }^{*}$ Faruk Skenderi, MD, MSc, 广 Vanesa Beslagic, MD, MSc, $\neq$ \\ and Zoran Gatalica, MD, DScई
}

\begin{abstract}
Glycogen-rich clear cell carcinoma (GRCC) is a very rare form of primary breast cancer $(<0.1 \%$ of all breast cancers). It is characterized by the presence of neoplastic cells with a glycogen-abundant clear cytoplasm (the Periodic Acid Schiffpositive, diastase-sensitive). The expression of steroid receptors (estrogen and progesterone receptors) has been variably reported (35\% to $100 \%$ of the cases), whereas most studies reported low human epidermal growth factor receptor 2 positivity in GRCC. High androgen receptor positivity without androgen receptor splice variant-7 was reported in one recent study. Although sparse, the preliminary theranostic data on GRCC indicate the potential of targeted treatments in selected cases (antiandrogen, PIK3CA, and immune checkpoint inhibitors). Because of its rarity, the prognosis for GRCC patients remains controversial. Herein, we comprehensively appraise the epidemiological, morphologic, molecular, and clinical characteristics of this rare mammary malignancy.
\end{abstract}

Key Words: breast cancer, special types, glycogen-rich carcinoma, clear cell carcinoma

(Appl Immunohistochem Mol Morphol 2020;00:000-000)

I nvasive breast carcinoma (IBC) is not one disease, but rather a heterogenous group of diseases, most of which possess a distinct morphology, molecular features, and clinical behavior. ${ }^{1}$ Irrespective of the morphology, all IBC are grouped into the following biomarker-defined subtypes on the basis of estrogen receptor (ER) and ERBB2 [human epidermal growth factor receptor (HER) 2] status: ER-positive/HER2-negative (luminal A); ER-positive/HER2-positive (luminal B); ERnegative/HER2-positive (HER2 ${ }^{+}$subtype); and ER-negative/ HER2-negative [triple-negative breast cancer (TNBC)/ subtype.$^{2}$

The term IBC of no special type (NST) refers to a large and heterogeneous group of IBCs that cannot be

\footnotetext{
Received for publication February 18, 2020; accepted February 22, 2020. From the *College of Medicine, QU Health, Qatar University, Doha, Qatar; Departments of $\uparrow$ Pathology; $\$$ Radiology, Clinical Center, University of Sarajevo, Sarajevo, Bosnia and Herzegovina; and $\S$ Creighton University School of Medicine, Phoenix, AZ.

The authors declare no conflict of interest.

Reprints: Semir Vranic, MD, PhD, College of Medicine, QU Health, Qatar University, Annex Building, Office \#10, P.O. Box 2713, Doha, Qatar (e-mails: semir.vranic@gmail.com; svranic@qu.edu.qa).

Copyright (C) 2020 Wolters Kluwer Health, Inc. All rights reserved.
}

classified morphologically as any of the special histologic types. ${ }^{2}$ IBC-NST is the most common morphologic subtype, whereas all other subtypes (= special histologic types) constitute $\sim 20 \%$ of all IBC.

Among the IBC-NST, several distinct morphologic patterns have been recognized including oncocytic, sebaceous, lipid-rich, and glycogen-rich/clear cell (GRCC) patterns. ${ }^{2}$ In addition, the most recent World Health Organization (WHO) classification acknowledged carcinomas with medullary, neuroendocrine, pleomorphic, osteoclast-like giant cells, choriocarcinomatous, and melanocytic features/patterns to be the spectrum of IBC-NST morphologies. Consequently, these cancers do not require the $90 \%$ rule for differentiation, which is applied for special histologic types. ${ }^{2}$

In the current review, we focus on the GRCC form of IBC-NST, providing its epidemiological, morphologic, ultrastructural, molecular, radiologic, and clinical characteristics.

\section{DEFINITION}

GRCC is a morphologic pattern of IBC-NST that is composed of neoplastic cells with abundant clear cytoplasm that contains glycogen. ${ }^{2}$ Given that cytoplasmic glycogen may be seen without a marked clear cell appearance and because clear cell morphology can be caused by substances other than glycogen, both features are required for the diagnosis of this specific pattern. ${ }^{2}$ Notably, Hull et $\mathrm{al}^{3}$ were the first to introduce and elucidate this peculiar entity in 1981 .

Clear cell changes may also affect normal and benign breast tissues. Thus, breast ducts and lobules may undergo clear changes during the pregnancy, where the clearing of the cytoplasm typically affects myoepithelial cells and the clearing of the cytoplasm that may be seen in benign changes such as apocrine metaplasia. ${ }^{4}$

\section{EPIDEMIOLOGY OF GRCC}

The actual incidence of GRCC is unknown, but most authors agree that it is a very uncommon pattern of IBC-NST. The largest to date study, based on the analysis from the Surveillance, Epidemiology and End Results (SEER) database, identified 155 cases of GRCC among the 1,251,584 cases of other (non-GRCC) breast carcinomas (frequency $\sim 0.01 \%$ ). ${ }^{5} \mathrm{~A}$ study of Toikkanen and Joensuu 6 revealed 6 cases of GRCC among the 439 cases of IBCs $(\sim 1.4 \%)$; a similar incidence $(1.8 \%)$ was reported by Nacul et $\mathrm{al}^{7}{ }^{7}$ whereas Kuroda et $\mathrm{al}^{8}$ reported 20 cases of GRCC among the 723 consecutive 
TABLE 1. Summary of the Published Studies ( $>5$ Cases/Patients) That Reported Steroid Receptor Profile, HER2 Status, and/or Follow-up Data on the Patients With Glycogen-rich Clear Cell Carcinoma

\begin{tabular}{|c|c|c|c|}
\hline References & No. Patients (Cases) & ER/PR/HER2 Status (\%) & Clinical Outcome (Survival) \\
\hline Skenderi et $\mathrm{al}^{9 *}$ & 9 & $88 / 88 / 0$ & Not reported \\
\hline Zhou et $\mathrm{al}^{5}$ & 155 (SEER) & $46.5 / 27 / 6.9$ & Worse than NST \\
\hline Chang et al ${ }^{10}$ & 5 & $100 / 0 / 0$ & Not reported \\
\hline Nacul et $\mathrm{al}^{7}$ & 17 & NA & Similar to NST (early stage) \\
\hline Akbulut et al ${ }^{12}$ & 37 & $62 / 43 / 44$ & Not reported \\
\hline Kuroda et $\mathrm{al}^{8}$ & 20 & $35 / 30 / 20$ & $5 / 15$ died of disease \\
\hline Varga et $\mathrm{al}^{13}$ & 12 & $75 / 75 / 25$ & $2 / 3$ positive axillary lymph nodes \\
\hline Hull and Warfel ${ }^{15}$ & 10 & NA (ultrastructural study) & $5 / 10$ died of the disease \\
\hline Fisher et $\mathrm{al}^{16}$ & 45 & NA & Worse than NST \\
\hline
\end{tabular}

*This is the only molecular genetic study on glycogen-rich clear cell carcinoma.

ER indicates estrogen receptor; HER2, human epidermal growth factor receptor 2; NA, not available; NST, no special type; PR, progesterone receptor; SEER, Surveillance, Epidemiology and End Results database.

patients with primary breast carcinomas $(\sim 2.8 \%)$. Our own experience also indicates a very low incidence of GRCC $(\sim 0.2 \%)$.

We conducted a comprehensive literature survey (PubMed/MEDLINE, Scopus, Web of Science) that revealed a vast majority of publications being single cases (case reports) and small case series ( $<20$ cases per study) (Tables 1,2$)$. We found only 6 larger studies reporting $>20$ GRCC cases (Table 1).

\section{HISTOLOGIC AND ULTRASTRUCTURAL FEATURES OF GRCC}

Similar to IBC-NST, most GRCCs exhibit a sheet-like, nested, or corded growth pattern ${ }^{14}$ (Fig. 1). Occasionally, the clear cells may be arranged in solid, papillary, micropapillary, cribriform, alveolar, lobular, and/or tubular patterns. 3,14,20-24 Rare cases of neuroendocrine, apocrine, and mucinous differentiation have also been well documented. 14,21,25

Most GRCC are diagnosed as invasive carcinomas. Rare cases of pure intraductal GRCC have also been described. 26,27

The cancer cells of GRCC have well-defined borders with polygonal contours (Fig. 1). ${ }^{28}$ The cytoplasm that is clear or finely granular contains the Periodic Acid Schiff (PAS)-positive, diastase-sensitive glycogen. ${ }^{29}$ The cell nuclei are oval our round, with a clumped chromatin and prominent nucleoli (Fig. 1). The nuclear atypia is usually moderate to marked, ${ }^{14,28,30,31}$ which corresponds to grade 2 or 3 according to the Nottingham histologic score.

Seminal papers of Hull and colleagues ${ }^{3,15}$ revealed the ultrastructural features of GRCC. According to Hull et al, ${ }^{15}$ neoplastic clear cells contain large quantities of "non-membrane-bound particulate glycogen and that formed numerous acini." On the apical site, the clear cells form microvilli while tight junctions and desmosomes are created on lateral sides. The intracellular content is typically PAS and digested with diastase, which is consistent with glycogen pools. These findings were further confirmed in subsequent studies of Fisher et al, ${ }^{16}$ Okamoto, ${ }^{23}$ Alexiev, ${ }^{30}$ and Fujino et al. ${ }^{22}$

\section{DIFFERENTIAL DIAGNOSIS}

Several breast cancers with clear cell cytoplasm should be considered in the differential diagnosis. Among these, lipidrich carcinoma, sebaceous carcinoma, secretory carcinoma, histiocytoid carcinoma, and myoepithelial tumors should be ruled out. ${ }^{2,32}$ In addition, apocrine carcinomas may also contain cells with foamy or clear cytoplasm ("type B" cells). ${ }^{33}$ Focal clear cell changes may also be encountered in other growth patterns of IBC including papillary, micropapillary,

TABLE 2. Summary of the Published Molecular Studies on Glycogen-rich Clear Cell Carcinoma

\begin{tabular}{|c|c|c|c|}
\hline References & No. Patients (Cases) & Method(s) & Molecular Features (Number of Positive/Total Number of Cases) \\
\hline Skenderi et $\mathrm{al}^{9}$ & 9 & IHC, ISH, NGS & $\begin{array}{l}\mathrm{AR}^{+}(7 / 9), \mathrm{ARv}^{+}(0 / 7), \mathrm{PD}^{-L 1} 1^{+}(3 / 8), \text { PIK3RI (1/5), PTEN (3/8), BRCA2 (1/5), } \\
\quad \text { TP53 (1/5), CDKN2A (1/5), BCOR (1/5), MSI-S (8/8) }\end{array}$ \\
\hline Chang et $\mathrm{al}^{10}$ & 5 & $\mathrm{IHC}$ & HepPar1 $^{+}(5 / 5)$, GATA3 $^{+}(5 / 5)$, AFP $^{-}(5 / 5)$ \\
\hline Kim et $\mathrm{al}^{18}$ & 3 & IHC & $\begin{array}{l}\mathrm{p}_{53}^{+}(1+/ 3) \text {; Ki-67 }(15-60 \%) \text {, E-cadherin }(2+/ 3) \text {, AR }(1+/ 3) \text {, p63 }(1+/ 3) \text {, cKit }(2+/ 3), \\
\text { EGFR }(2+/ 3), \text { GCDFP-15 (0/3), Galectin-3 }(2+/ 3)\end{array}$ \\
\hline Varga and Caduff ${ }^{19}$ & 6 & IHC and TUNEL & Low proliferation rate $(\mathrm{Ki}-67)$ and low apoptotic rate \\
\hline Toikkanen and Joensuu ${ }^{6}$ & 6 & Flow cytometry & Nondiploid cancers with a high S-phase fraction \\
\hline
\end{tabular}

AFP indicates alpha-fetoprotein; AR, androgen receptor; EGFR, epidermal growth factor receptor; FISH, fluorescence in situ hybridization; GCDFP-15, gross cystic disease fluid protein 15; IHC, immunohistochemistry; ISH, in situ hybridization; MSI-S, microsatellite instability stable; NGS, next-generation sequencing; PD-L1, programmed death receptor ligand 1; qPCR, quantitative polymerase chain reaction; TUNEL, terminal deoxynucleotidyl transferase dUTP nick end labeling. 


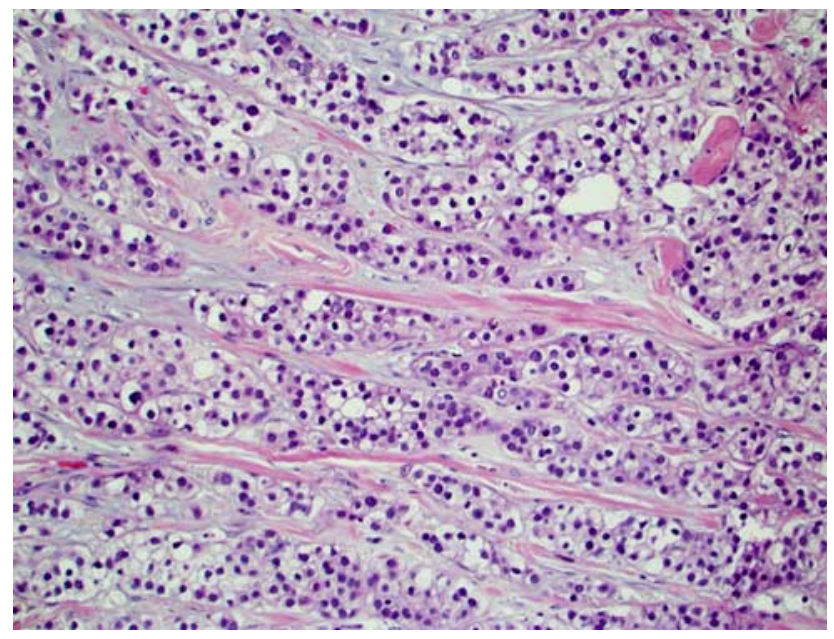

FIGURE 1. Hematoxylin and eosin slide of a case of invasive beast carcinoma with a predominant clear cell morphology ( $>90 \%$ of cancer cells).

mucinous, and neuroendocrine carcinomas. Rarely, benign and malignant myoepithelial lesions of the breast may have prominent clear cell differentiation and should be differentiated from GRCC. ${ }^{34-36}$ Govender et $\mathrm{al}^{37}$ described an exceptional case of a primary clear cell "sugar" tumor of the breast in a 16-year-old girl. These tumors belong to a broader family of perivascular epithelioid cell tumors that were originally described in the lung and later at several extrapulmonary sites (eg, kidneys, gastrointestinal tract, uterus). ${ }^{37,38}$ Several additional cases of perivascular epithelioid cell tumors of the breast have been well documented. ${ }^{39-41}$

In most of these cases, special stains (PAS and PASdiastase) along with an appropriate immunohistochemical algorithm are helpful to confirm the presence of intracytoplasmic glycogen and to render the correct diagnosis. In case of secretory carcinoma, the detection of specific chromosomal translocation $\mathrm{t}(12 ; 15)(\mathrm{p} 13 ; \mathrm{q} 25)$, resulting in the ETV6-NTRK3 fusion gene, rules out the GRCC. ${ }^{42}$

Although nonprimary cancers with clear cell histology involving the breast (eg, metastatic clear cell renal cell carcinoma, melanomas, and soft tissue tumors with clear cell morphology) are extremely rare, they should also be considered in the differential diagnosis. In all these cases, the clinical history of the primary site along with a meticulous immunohistochemical panel may lead to the correct diagnosis.

\section{STEROID RECEPTORS IN GRCC}

ER positivity has been reported in $35 \%$ to $100 \%$ of cases, whereas the PR positivity appears to be markedly lower (range in the reported studies $0 \%$ to $88 \%$; most of the reported studies reported PR positivity $<30 \%$ ) (Table 1). This is in line with the data from the SEER database, where the ER positivity rate in GRCC was $\sim 47 \%$ and $27 \%$ for PR. ${ }^{5}$

The expression of androgen receptor (AR) was recently reported in $88 \%$ of GRCC cases. ${ }^{9}$ Notably, none of the AR-positive GRCC harbored androgen receptor splice variant-7 (ARv7) (Table 2). $A R v 7$ encodes a truncated AR protein that lacks the ligand-binding domain and is constitutively active in the absence of androgens. ${ }^{43}$

\section{HER RECEPTORS FAMILY IN GRCC}

HER2 expression in GRCC has been variably reported in the literature (Table 1). Akbulut et $\mathrm{al}^{12}$ reported the highest rate (44\%) of HER2 positivity in GRCC. However, in the SEER cohort of GRCC $(n=155)$, HER2 expression was observed in only $\sim 7 \%$ of GRCC. ${ }^{5}$ Our experience $(n=9)$ also indicates a low HER2 protein expression in GRCCs. In addition, HER2 gene mutations have not been reported in GRCC. ${ }^{9}$

Two separate studies revealed EGFR activation in 2 GRCC cases, with one of the cases harboring a unique EGFR mutation and gene amplification. ${ }^{17,18}$ Our study, based on NGS analysis of 5 GRCC cases, revealed no $E G F R$ genomic alterations in this cancer. ${ }^{9} E R B B 3$ (HER3) and ERBB4 (HER4) mutations were not detected in GRCC either. ${ }^{9}$

\section{MOLECULAR GENETIC CHARACTERISTICS OF GRCC}

Apart from steroid receptors and HER2/neu, the molecular features of GRCC are largely unknown. Very few studies specifically addressed GRCC molecular portraits and typically used limited technologies (summarized in Table 2). There is no single microarray (gene expression profiling) study on GRCC of the breast.

Two studies revealed a low proliferation rate of GRCC, ${ }^{17,19}$ whereas the study of Toikkanen and Joensuu ${ }^{6}$ indicated a nondiploid nature of GRCC with a high S-phase fraction. Another study carried out by Kim et $\mathrm{al}^{18}$ revealed a variable Ki-67 expression in 3 GRCC cases (15-\% to 60\%).

Similar to other breast cancer subtypes and cancer in general, the TP53 gene appears to be involved in a subset of GRCCs. ${ }^{9,18,28}$ Ma et $\mathrm{al}^{11}$ reported $\sim 46 \%$ of GRCC cases $(n=28)$ to be $p 53$ positive by immunohistochemistry. A study by Chang et $\mathrm{a}^{10}$ also confirmed a common expression of GATA3 protein. GATA3 (= GATA Binding Protein 3) acts as a transcription factor and is closely linked to ER function in breast carcinoma. ${ }^{44}$ Although not specific for breast, GATA3 is commonly overexpressed and is one of the most frequently mutated genes in breast carcinoma. ${ }^{45}$ In a clinical setting, GATA 3 has been frequently used in the breast panel to differentiate mammary origins from nonmammary types of cancers. The same study also revealed HepParl to be expressed in GRCC. ${ }^{10}$ HepParl is a useful biomarker in detecting hepatocellular origins of the cancer cells, whereas its expression in breast cancer has rarely been described. ${ }^{46} \mathrm{In}$ contrast to hepatocellular carcinomas, all GRCC were negative for alpha-fetoprotein. ${ }^{10}$

The only comprehensive theranostic study on GRCC was carried out by our research group. ${ }^{9}$ Although limited to a small number of tested cases, our study revealed several novel predictive biomarkers that could guide tailored therapeutics for patients with advanced/metastatic GRCC. The high expression of $\mathrm{AR}$ without the presence of its splice variant ARv7 indicates a rationale for treatment with anti-AR modalities. 
Multiple studies have reported AR expression across the breast cancer subtypes including special types and rare morphologic patterns. ${ }^{4-49}$ Most of them revealed the predominance of $\mathrm{AR}$ expression among ER-positive (luminal) breast cancers, although up to $20 \%$ of TNBC may also overexpress AR ${ }^{50-53}$ Several clinical trials with anti-AR treatment modalities in AR-positive breast cancers have shown potential therapeutic effects. ${ }^{48,54-57}$ However, ARv7 has recently emerged as an important predictive biomarker that is frequently expressed in advanced prostate carcinomas resistant to anti-AR treatment modalities. ${ }^{43}$ ARv7 has also been reported in breast cancer. ${ }^{58,59}$ However, the clinical utility of both AR and ARv7 in breast cancer remains to be elucidated, given that antiandrogens have not been approved yet for the treatment of breast cancer.

A subset of GRCC was also enriched with the molecular alterations within the PIK3CA/PTEN pathway. In particular, PTEN appears to be downregulated, even in the absence of PTEN gene mutations. ${ }^{9}$ This may be therapeutically relevant, given that the Food and Drug Administration (FDA) approved Piqray (alpelisib) in combination with fulvestrant (an ER antagonist) for the treatment of $\mathrm{ER}^{+} / \mathrm{HER} 2^{-}$, PIK3CA-mutated advanced/ metastatic breast carcinomas.

Given the common AR expression among the PIK3CA/PTEN altered GRCCs, there is a therapeutic potential in combined treatment modalities. Thus, Lehmann et $\mathrm{al}^{54}$ recently demonstrated the therapeutic benefits of combined anti-AR enzalutamide with the PIK3CA inhibitor taselisib in TNBC expressing AR.

The therapy with immune checkpoint inhibitors [against programmed cell death protein $1 /$ programmed death receptor ligand 1 (PD-L1)] has markedly improved the treatment and outcome of several cancers including TNBCs (IMpassion130 clinical trial, ID: NCT02425891). Several biomarkers have been shown to have the predictive value including PD-L1 expression in cancer or immune cells, high microsatellite instability (MSI) status, and high tumor mutational burden (TMB). ${ }^{60,61}$ Most studies reported breast cancers to be MSIstable with low TMB and variable PD-L1 expression (more commonly in immune cells in HER $2^{+}$and TNBC subtypes). ${ }^{60}$ In the case of breast cancer, PD-L1 expression on immune cells has been confirmed as a predictive biomarker of response and was approved as a companion diagnostic test along with anti-PD-L1 drug atezolizumab. ${ }^{60,62}$ The threshold for PD-L1 positivity was set at $\geq 1 \%$ area occupied by $\mathrm{PD}-\mathrm{L}^{+}$immune cells. ${ }^{63}$ Our study indicates the presence of PD-L1 in immune cells ( $1 \%$ to $10 \%$ positivity) in a subset of GRCC, whereas high-TMB and MSI-high were not observed in GRCC. ${ }^{9}$ This profile is similar to IBC-NST with similar molecular features $\left(\mathrm{ER}^{+} / \mathrm{HER} 2^{-}\right.$phenotype). PTEN loss has been associated with the resistance to immune checkpoint inhibitors. ${ }^{64-66} \mathrm{It}$ has been shown that PTEN downregulation may induce cytokine secretion and reduce the number of TILs, thus creating an immune-suppressive microenvironment. ${ }^{67}$ However, PTEN loss was observed in only 1 of 3 PD-L1 $1^{+}$GRCC. ${ }^{9}$ On the basis of these findings, a subset of PD-L1 ${ }^{+}$GRCCs may be potentially eligible for the trials with immune checkpoint inhibitors.

\section{RADIOLOGIC AND CLINICAL CHARACTERISTICS OF GRCC}

Radiologic data on the GRCC are relatively sparse. ${ }^{68}$ Eun et $\mathrm{a}^{68}$ recently published a detailed radiologic description of 3 GRCCs and provided an excellent review of the previously published radiologic studies on GRCC. They found GRCC to present as a mass with irregular or oval shapes (mammography) and as a complex cystic and/or solid mass on ultrasound. ${ }^{68} \mathrm{Ma}$ et $\mathrm{al}^{11}$ also reported the radiologic features of GRCC $(n=28)$. Similar to IBC-NST, most GRCC presented mammographically as a high-density mass with intratumoral calcifications. ${ }^{11}$ Ultrasonography usually reveals a hypoechoic mass with calcifications. ${ }^{11}$ However, calcifications may not be seen and GRCCs may present as irregular, spiculated, and hyperdense masses. ${ }^{68,69}$ Magnetic resonance imaging findings are also similar to IBC-NST, showing irregular masses with enhancement. ${ }^{70}$

The prognosis of GRCC is still controversial. Several studies suggested that GRCC tends to follow an aggressive clinical course, ${ }^{5,71}$ but other studies have indicated that the prognosis was not significantly different from that of IBC-NST when matched for tumor size, grade, and lymph node status. ${ }^{11,70,72,73}$

The most comprehensive clinical study on GRCC was based on the SEER database. ${ }^{5}$ The study compared the clinicopathologic characteristics of 155 GRCC with a large cohort (>1.2 million) of non-GRCC breast cancers. It revealed that GRCC cases were more likely to be grade 3 carcinomas with a triple-negative phenotype $(\sim 45 \%)$ presenting at an advanced clinical stage. ${ }^{5}$ Overall survival of GRCC was worse compared with non-GRCC breast carcinomas. ${ }^{5} \mathrm{Ma}$ et $\mathrm{al},{ }^{11}$ in another study, found the number of positive axillary lymph nodes to be a strong predictor of survival among the GRCC patients. However, when matched with IBC-NST, the authors found no significant difference in survival among the GRCC patients. ${ }^{11}$

\section{CONCLUSIONS}

GRCC is an extremely rare breast cancer subtype. It tends to be an ER-positive $(\sim 50 \%)$, PR-negative, and HER2-negative subtype with an unfavorable clinical outcome compared with matched IBCs of NST. Although sparse, the preliminary theranostic data on GRCC indicate the potential of targeted treatments in selected cases (antiandrogen, PIK3$\mathrm{CA}$, and immune checkpoint inhibitors). Additional molecular studies that would depict its molecular characteristics are needed. Such studies would not only enhance the knowledge on GRCC but would also pave the way for novel treatment modalities for this peculiar mammary malignancy.

\section{REFERENCES}

1. Cancer Genome Atlas Network. Comprehensive molecular portraits of human breast tumours. Nature. 2012;490:61-70.

2. WHO Classification of Tumours Editorial Board. Breast Tumours, Volume 2, 5th ed. Lyon, France: IARC; 2019.

3. Hull MT, Priest JB, Broadie TA, et al. Glycogen-rich clear cell carcinoma of the breast: a light and electron microscopic study. Cancer. 1981;48:2003-2009.

4. Ovanez C, Crawford J, Asarian A, et al. Invasive ductal carcinoma of the breast with clear cell and pseudo-lactating changes. $J$ Surg Case Rep. 2014;2014:pii:rju063. 
5. Zhou Z, Kinslow CJ, Hibshoosh H, et al. Clinical features, survival and prognostic factors of glycogen-rich clear cell carcinoma (GRCC) of the breast in the US population. J Clin Med. 2019;8:pii:E246.

6. Toikkanen S, Joensuu H. Glycogen-rich clear-cell carcinoma of the breast: a clinicopathologic and flow cytometric study. Hum Pathol. 1991;22:81-83.

7. Nacul MJ, Gerardi CG, Japaze H, et al. Early stages of clear cell (glycogen rich cell) invasive ductal carcinoma (IDC) of the breast: good or bad prognosis? J Clin Oncol. 2011;29(suppl):e11053.

8. Kuroda H, Sakamoto G, Ohnisi K, et al. Clinical and pathological features of glycogen-rich clear cell carcinoma of the breast. Breast Cancer. 2005;12:189-195.

9. Skenderi F, Palazzo J, Swensen J, et al. Molecular profiling of clear cell carcinoma of the breast reveals novel targetable biomarkers. Mod Pathol. 2020;33(suppl 2):263.

10. Chang MC, Wu JM, Bethune GC. 77PHep par 1 immunohistochemistry in glycogen-rich clear cell carcinoma of the breast. Ann Oncol. 2019;30(suppl 3):iii23.

11. Ma X, Han Y, Fan Y, et al. Clinicopathologic characteristics and prognosis of glycogen-rich clear cell carcinoma of the breast. Breast J. 2014;20:166-173.

12. Akbulut M, Zekioglu O, Kapkac M, et al. Fine needle aspiration cytology of glycogen-rich clear cell carcinoma of the breast: review of 37 cases with histologic correlation. Acta Cytol. 2008;52:65-71.

13. Varga Z, Zhao J, Ohlschlegel C, et al. Preferential HER-2/neu overexpression and/or amplification in aggressive histological subtypes of invasive breast cancer. Histopathology. 2004;44:332-338.

14. Hayes MM, Seidman JD, Ashton MA. Glycogen-rich clear cell carcinoma of the breast. A clinicopathologic study of 21 cases. Am J Surg Pathol. 1995;19:904-911.

15. Hull MT, Warfel KA. Glycogen-rich clear cell carcinomas of the breast. A clinicopathologic and ultrastructural study. Am J Surg Pathol. 1986;10:553-559.

16. Fisher ER, Tavares J, Bulatao IS, et al. Glycogen-rich, clear cell breast cancer: with comments concerning other clear cell variants. Hum Pathol. 1985;16:1085-1090.

17. Levva S, Kotoula V, Kostopoulos I, et al. Prognostic evaluation of epidermal growth factor receptor (EGFR) genotype and phenotype parameters in triple-negative breast cancers. Cancer Genomics Proteomics. 2017; 14:181-195.

18. Kim SE, Koo JS, Jung WH. Immunophenotypes of glycogen rich clear cell carcinoma. Yonsei Med J. 2012;53:1142-1146.

19. Varga Z, Caduff R. Glycogen-rich carcinomas of the breast display unique characteristics with respect to proliferation and the frequency of oligonucleosomal fragments. Breast Cancer Res Treat. 1999;57: 215-219.

20. Benisch B, Peison B, Newman R, et al. Solid glycogen-rich clear cell carcinoma of the breast (a light and ultrastructural study). Am J Clin Pathol. 1983;79:243-245.

21. Sorensen FB, Paulsen SM. Glycogen-rich clear cell carcinoma of the breast: a solid variant with mucus. A light microscopic, immunohistochemical and ultrastructural study of a case. Histopathology. 1987;11: 857-869.

22. Fujino S, Tezuka N, Sawai S, et al. Glycogen-rich clear cell carcinoma of the breast: a case report and review of the literature. Breast Cancer. 1996;3:205-208.

23. Okamoto T. Glycogen-rich clear cell carcinoma of the breast. An autopsy case. Acta Pathol Jpn. 1989;39:469-472.

24. Solanki MH, Derylo AF, Jorns JM. Invasive mammary carcinoma with mixed invasive papillary and glycogen rich clear cell features. Int J Surg Pathol. 2018;26:569-572.

25. Di Tommaso L, Pasquinelli G, Portincasa G, et al. Glycogen-rich clear-cell breast carcinoma with neuroendocrine differentiation features. Pathologica. 2001;93:676-680.

26. Salemis NS. Intraductal glycogen-rich clear cell carcinoma of the breast: a rare presentation and review of the literature. Breast Care (Basel). 2012;7:319-321.

27. Seki H, Sasaki K, Morinaga S, et al. A case of glycogen-rich clear cell carcinoma of the breast with extensive intraductal components and micrometastases to the axillary lymph node. Gan To Kagaku Ryoho. 2016;43:239-241.
28. Takekawa Y, Kubo A, Morita T, et al. Histopathological and immunohistochemical findings in a case of glycogen-rich clear cell carcinoma of the breast. Rinsho Byori. 2006;54:27-30.

29. Satake N, Uehara H, Sano N, et al. Cytological analysis of glycogenrich carcinoma of the breast: report of two cases. J Med Invest. 2002;49:193-196.

30. Alexiev BA. Glycogen-rich clear cell carcinoma of the breast: report of a case with fine-needle aspiration cytology and immunocytochemical and ultrastructural studies. Diagn Cytopathol. 1995;12:62-66.

31. Das AK, Verma K, Aron M. Fine-needle aspiration cytology of glycogen-rich carcinoma of breast: report of a case and review of literature. Diagn Cytopathol. 2005;33:263-267.

32. Kern SB, Andera L. Cytology of glycogen-rich (clear cell) carcinoma of the breast. A report of two cases. Acta Cytol. 1997;41:556-560.

33. Vranic S, Schmitt F, Sapino A, et al. Apocrine carcinoma of the breast: a comprehensive review. Histol Histopathol. 2013;28:1393-1409.

34. Kuwabara H, Uda H. Clear cell mammary malignant myoepithelioma with abundant glycogens. J Clin Pathol. 1997;50:700-702.

35. Son HJ, Jung SH, Lee SY, et al. Glycogen-rich clear cell mammary malignant myoepithelioma. Breast. 2004;13:506-509.

36. Suguna BV, Geethamani V, Niveditha SR, et al. Malignant myoepithelioma of the breast: case report with review of literature. Malays J Pathol. 2011;33:125-128.

37. Govender D, Sabaratnam RM, Essa AS. Clear cell 'sugar' tumor of the breast: another extrapulmonary site and review of the literature. Am J Surg Pathol. 2002;26:670-675.

38. Hornick JL, Fletcher CD. PEComa: what do we know so far? Histopathology. 2006;48:75-82.

39. Kim H, Kim J, Lee SK, et al. TFE3-expressing perivascular epithelioid cell tumor of the breast. J Pathol Transl Med. 2019;53:62-65.

40. Crocetti D, Pedulla G, Tarallo MR, et al. A rare case of malignant epithelioid angiomyolipoma in multiple locations: multifocal disease or metastases? Ann Ital Chir. 2014;85:184-188.

41. Damiani S, Chiodera P, Guaragni M, et al. Mammary angiomyolipoma. Virchows Arch. 2002;440:551-552.

42. Tognon C, Knezevich SR, Huntsman D, et al. Expression of the ETV6-NTRK3 gene fusion as a primary event in human secretory breast carcinoma. Cancer Cell. 2002;2:367-376.

43. Zhang T, Karsh LI, Nissenblatt MJ, et al. Androgen receptor splice variant, $\mathrm{AR}-\mathrm{V} 7$, as a biomarker of resistance to androgen axistargeted therapies in advanced prostate cancer. Clin Genitourin Cancer. 2020;18:1-10.

44. Ciocca V, Daskalakis C, Ciocca RM, et al. The significance of GATA3 expression in breast cancer: a 10-year follow-up study. Hum Pathol. 2009;40:489-495.

45. Gaynor KU, Grigorieva IV, Allen MD, et al. GATA3 mutations found in breast cancers may be associated with aberrant nuclear localization, reduced transactivation and cell invasiveness. Horm Cancer. 2013;4:123-139.

46. Siddiqui MT, Saboorian MH, Gokaslan ST, et al. Diagnostic utility of the HepParl antibody to differentiate hepatocellular carcinoma from metastatic carcinoma in fine-needle aspiration samples. Cancer. 2002;96:49-52.

47. Pietri E, Conteduca V, Andreis D, et al. Androgen receptor signaling pathways as a target for breast cancer treatment. Endocr Relat Cancer. 2016;23:R485-R498.

48. Kono M, Fujii T, Lim B, et al. Androgen receptor function and androgen receptor-targeted therapies in breast cancer: a review. JAMA Oncol. 2017;3:1266-1273.

49. Anestis A, Zoi I, Papavassiliou AG, et al. Androgen receptor in breast cancer-clinical and preclinical research insights. Molecules. 2020;25:pii:E358.

50. Rampurwala M, Wisinski KB, O’Regan R. Role of the androgen receptor in triple-negative breast cancer. Clin Adv Hematol Oncol. 2016;14:186-193

51. Gerratana L, Basile D, Buono G, et al. Androgen receptor in triple negative breast cancer: a potential target for the targetless subtype. Cancer Treat Rev. 2018;68:102-110.

52. Bhattarai S, Klimov S, Mittal K, et al. Prognostic role of androgen receptor in triple negative breast cancer: a multi-institutional study. Cancers (Basel). 2019;11:pii:E995. 
53. Millis SZ, Gatalica Z, Winkler J, et al. Predictive biomarker profiling of $>6000$ breast cancer patients shows heterogeneity in TNBC, with treatment implications. Clin Breast Cancer. 2015;15:473.e3-481.e3.

54. Lehmann BD, Abramson VG, Sanders M, et al. TBCRC 032 IB/II multicenter study: molecular insights to AR antagonist and PI3K inhibitor efficacy in patients with AR+ metastatic triple-negative breast cancer. Clin Cancer Res. 2019. [Epub ahead of print].

55. Traina TA, Miller K, Yardley DA, et al. Enzalutamide for the treatment of androgen receptor-expressing triple-negative breast cancer. J Clin Oncol. 2018;36:884-890.

56. Bonnefoi $\mathrm{H}$, Grellety $\mathrm{T}$, Tredan $\mathrm{O}$, et al. A phase II trial of abiraterone acetate plus prednisone in patients with triple-negative androgen receptor positive locally advanced or metastatic breast cancer (UCBG 12-1). Ann Oncol. 2016;27:812-818.

57. Gucalp A, Tolaney S, Isakoff SJ, et al. Phase II trial of bicalutamide in patients with androgen receptor-positive, estrogen receptor-negative metastatic breast cancer. Clin Cancer Res. 2013;19:5505-5512.

58. Hickey TE, Irvine CM, Dvinge H, et al. Expression of androgen receptor splice variants in clinical breast cancers. Oncotarget. 2015;6:44728-44744.

59. Hu DG, Hickey TE, Irvine C, et al. Identification of androgen receptor splice variant transcripts in breast cancer cell lines and human tissues. Horm Cancer. 2014;5:61-71.

60. Vranic S, Cyprian FS, Gatalica Z, et al. PD-L1 status in breast cancer: current view and perspectives. Semin Cancer Biol. 2019. [Epub ahead of print].

61. Rizvi NA, Hellmann MD, Snyder A, et al. Cancer immunology. Mutational landscape determines sensitivity to PD-1 blockade in non-small cell lung cancer. Science. 2015;348:124-128.

62. Cyprian FS, Akhtar S, Gatalica Z, et al. Targeted immunotherapy with a checkpoint inhibitor in combination with chemotherapy: a new clinical paradigm in the treatment of triple-negative breast cancer. Bosn J Basic Med Sci. 2019;19:227-233.
63. Schmid P, Adams S, Rugo HS, et al. Atezolizumab and Nabpaclitaxel in advanced triple-negative breast cancer. $N$ Engl $J$ Med. 2018;379:2108-2121.

64. George S, Miao D, Demetri GD, et al. Loss of PTEN is associated with resistance to anti-PD-1 checkpoint blockade therapy in metastatic uterine leiomyosarcoma. Immunity. 2017;46:197-204.

65. Kakavand H, Jackett LA, Menzies AM, et al. Negative immune checkpoint regulation by VISTA: a mechanism of acquired resistance to anti-PD-1 therapy in metastatic melanoma patients. Mod Pathol. 2017;30:1666-1676.

66. Kalbasi A, Ribas A. Tumour-intrinsic resistance to immune checkpoint blockade. Nat Rev Immunol. 2020;20:25-39.

67. Cretella D, Digiacomo G, Giovannetti E, et al. PTEN alterations as a potential mechanism for tumor cell escape from PD-1/PD-L1 inhibition. Cancers (Basel). 2019;11:1318.

68. Eun NL, Cha YJ, Son EJ, et al. Clinical imaging of glycogen-rich clear cell carcinoma of the breast: a case series with literature review. Magn Reson Med Sci. 2019;18:238-242.

69. Mizukami Y, Takayama T, Takemura A, et al. Glycogen-rich clear cell carcinoma of the breast: a case report. J Med Ultrason (2001). 2009;36:39-43.

70. Baslaim MM, Junainah EM, Ahmad HH, et al. Glycogen rich clear cell carcinoma (GRCC) of the breast may not have a poor prognosis. Int J Surg Case Rep. 2017;33:92-96.

71. Ratti V, Pagani O. Clear cell carcinoma of the breast: a rare breast cancer subtype - case report and literature review. Case Rep Oncol. 2015;8:472-477.

72. Markopoulos C, Mantas D, Philipidis T, et al. Glycogen-rich clear cell carcinoma of the breast. World J Surg Oncol. 2008;6:44.

73. Al-Musaifer BM, Nagaraj V, Al-Buainain L, et al. Glycogen rich clear cell carcinoma of the breast: a rare subtype with good prognosis. J Surg Case Rep. 2019;2019:rjz150. 